\title{
Thickening of young Pacific lithosphere from high-resolution Rayleigh wave tomography: A test of the conductive cooling model
}

\author{
Nicholas Harmon $^{\mathrm{a}, *}$, Donald W. Forsyth ${ }^{\mathrm{b}}$, Dayanthie S. Weeraratne ${ }^{\mathrm{c}}$ \\ a University of California, San Diego, 9500 Gilman Drive, MC \#0225, La Jolla, CA 92093, United States \\ b Brown University, Department of Geological Sciences, Box 1846, Providence, RI 02912, United States \\ c California State University, Northridge, Department of Geological Sciences, 18111 Nordhoff Street, Northridge, CA 91330, United States
}

\section{A R T I C L E I N F O}

\section{Article history:}

Received 14 July 2008

Received in revised form 31 October 2008

Accepted 23 November 2008

Available online 25 December 2008

Editor: R.D. van der Hilst

\section{Keywords:}

East Pacific Rise

lithosphere

MELT

GLIMPSE

seismology

surface waves

\begin{abstract}
A B S T R A C T
Direct seismic measurements of the thickening of oceanic lithosphere away from the spreading axis are rare due to the remoteness of mid ocean ridges. On the East Pacific Rise, at $17^{\circ} \mathrm{S}$, there were two long-term broadband ocean bottom seismometer deployments, the MELT and GLIMPSE experiments. These arrays spanned young Pacific plate seafloor ranging in age from 0 to $8 \mathrm{Ma}$. Combining these two data sets, we describe the increase in Rayleigh wave phase velocities for 16-100 s period as function of distance from the ridge with two parameterizations: an arbitrary function of seafloor age and a simple polynomial function of age on the Pacific and Nazca plates. Although resolution analysis shows that 10 to 15 independent pieces of information about the age variation of phase velocity on the Pacific plate can be resolved at periods of $\leq 50 \mathrm{~s}$, the three parameter polynomial model fits the data almost as well, indicating a simple pattern of the evolution of structure with age.

To compare our observations to the predictions for the conductive cooling of the lithosphere, we convert a thermal half-space cooling model to shear velocity using anharmonic and anelastic contributions. The patterns in the velocities are not consistent with simple conductive cooling. The conductive cooling model under predicts the changes in phase velocity with age observed in the 20 to $78 \mathrm{~s}$ period range. We observe significant changes in shear velocity in the asthenosphere at depths greater than conductive cooling should extend. The asthenospheric low velocity zone is asymmetric, dipping to the west with the lowest velocities beneath the Pacific plate west of the spreading center. The conductive cooling model also over predicts the shear velocities in the lithosphere by $\sim 0.2 \mathrm{~km} / \mathrm{s}$. These anomalies indicate that more complicated mantle flow and significant mantle heterogeneities such as melt are required.
\end{abstract}

(c) 2008 Elsevier B.V. All rights reserved.

\section{Introduction}

Conductive cooling of the seafloor results in lithosphere that is progressively thicker and denser with increasing age or distance from the spreading axis, leading to seafloor subsidence, a reduction in heat flow on older seafloor and thickening of the seismically fast lid. Heat flow measurements on well sedimented seafloor and bathymetry are explained successfully with simple conductive cooling plate or halfspace thermal models in seafloor younger than about $80 \mathrm{Ma}$ (e.g. Mckenzie, 1967; Parker and Oldenburg, 1973; Parsons and Sclater, 1977; Stein and Stein, 1992). The increase in shear velocity of the uppermost mantle with increasing age observed with surface wave dispersion is also well described by these simple thermal models that predict deepening of isotherms in proportion to the square root of age in young seafloor (Faul and Jackson, 2005; Forsyth, 1975; Kausel et al.,

\footnotetext{
* Corresponding author. Tel.: +1 858534 9430; fax: +1 8585345332

E-mail addresses: nharmon@ucsd.edu (N. Harmon), Donald_Forsyth@brown.edu (D.W. Forsyth),dsw@csun.edu (D.S. Weeraratne).
}

1974; Maggi et al., 2006; Nishimura and Forsyth, 1988; Ritzwoller et al., 2004).

There are several indications, however, that the evolution of the oceanic lithosphere is more complex than is represented by these simple thermal models. First, a discontinuity at the base of the lithosphere has been observed in receiver function studies (Collins et al., 2002; Li et al., 2004; Vinnik et al., 2005), with whole mantle ScS reverberations (Courtier et al., 2007; Gaherty et al., 1996; Revenaugh and Jordan, 1991), and with multiple S waveforms (Tan and Helmberger, 2007). No discontinuity is expected from temperature sensitivity alone and there is no indication that the depth of the discontinuity is dependent on the age of the seafloor. Second, a magnetotelluric study of the East Pacific Rise (EPR) found a resistive layer that is about $60 \mathrm{~km}$ thick, independent of age (Evans et al., 2005), extending roughly to the depth to the seismic discontinuity reported elsewhere. Third, seismic velocity anomalies extend to greater depth and change more rapidly with distance from the East Pacific Rise axis than expected if simple conductive cooling from above is the primary control on structure (Dunn and Forsyth, 2003; Forsyth, 1977; Hammond and Toomey, 2003). Finally, the presence of pronounced 
asymmetries across spreading centers (Evans et al., 1999; Forsyth et al., 1998; Key and Constable, 2008; Toomey et al., 2007) suggests that flow in the mantle is more complex than is assumed in the simple models. As pointed out by many of these authors and others, the presence of water and/or melt in the asthenosphere and a dehydrated lithosphere following extraction of melt are probably necessary to explain the pattern of velocity and conductivity anomalies. Nevertheless, some recent studies have suggested that neither the effects of melt nor water are required to explain the seismological observations if the non-linear, anelastic effects of attenuation due to changes in temperature or grain size on velocity are considered within the context of cooling plate or cooling half-space models (Faul and Jackson, 2005; Priestley and McKenzie, 2006).

The purpose of this paper is to test the simple conductive cooling model of the evolution of the Pacific lithosphere by comparing predictions of the model to higher resolution measurements of the dispersion of Rayleigh surface waves than have previously been available. Most previous studies of lithospheric evolution have used long paths crossing the oceans to land stations. Using data from the longterm ocean bottom seismometer deployments of the MELT and GLIMPSE experiments near $17^{\circ} \mathrm{S}$ on the East Pacific Rise (EPR) provides an order of magnitude better spatial resolution than is available from conventional teleseismic studies. Fig. 1 shows the regional bathymetry and station locations of the two experiments. The combined study areas cover seafloor of 0-8 Ma in age near one of the longest segments of the EPR, with control from crossing paths extending to $\sim 10 \mathrm{Ma}$. The EPR in this region has a half spreading rate of $72 \mathrm{~mm} / \mathrm{yr}$, and is migrating to the west at $30 \mathrm{~mm} / \mathrm{yr}$. The subsidence of the Pacific plate is slower than on the Nazca plate suggesting that there is hotter mantle beneath the Pacific plate (Cochran, 1986). Body wave delays and tomography from these two experiments show a thickening seismically fast lithosphere underlain by slower mantle material to the west, but the lateral resolution was insufficient to fully quantify the change with age of the lithosphere (Harmon et al., 2007a,b; Toomey et al., 1998).
In this study, we determine a functional form for the change in Rayleigh wave phase velocities with seafloor age on the Pacific plate using the data from MELT and GLIMPSE studies. We show there is a significant square-root-of-age relationship at short periods for the Rayleigh wave data that is consistent with conductive cooling, but that there are other features of the dispersion that are not predicted by simple models of mantle flow or the thermal and anelastic effects on shear velocity.

\section{Rayleigh wave inversion}

We invert the Fourier components (real and imaginary) of the bandpass filtered and windowed Rayleigh wave vertical and pressure records for phase velocities, station corrections, and incoming wavefield parameters using the method of Forsyth and Li (2005). The method accounts for deviations from a great circle path and scattering effects caused by heterogeneities between the source and receiver array with a two interfering plane wave approximation; this approximation has 6 wavefield parameters for each event. After Yang and Forsyth (2006), we use the Gaussian smoothed finite-frequency sensitivity kernels of Zhou et al. (2004) for amplitude and phase to account for focusing and scattering effects from heterogeneities in the vicinity of the array. Station amplitude corrections are included in the inversion to account for incorrect station responses, which are primarily important for the sites with differential pressure gauges that have imperfectly calibrated gains.

The inversion at each period is made of two sets of 10 iterations. All data are initially given equal weight in the first set of inversions, and then re-weighted by the misfit of each event, so that poorly fit events are down-weighted. Each iteration of the inversion scheme is a twostep process. First, a simulated annealing inversion is performed to find the best fitting two-plane wave approximation to the observed wavefield for each event. In the second stage, we use the wavefield approximation as the starting model for a linearized damped iterative

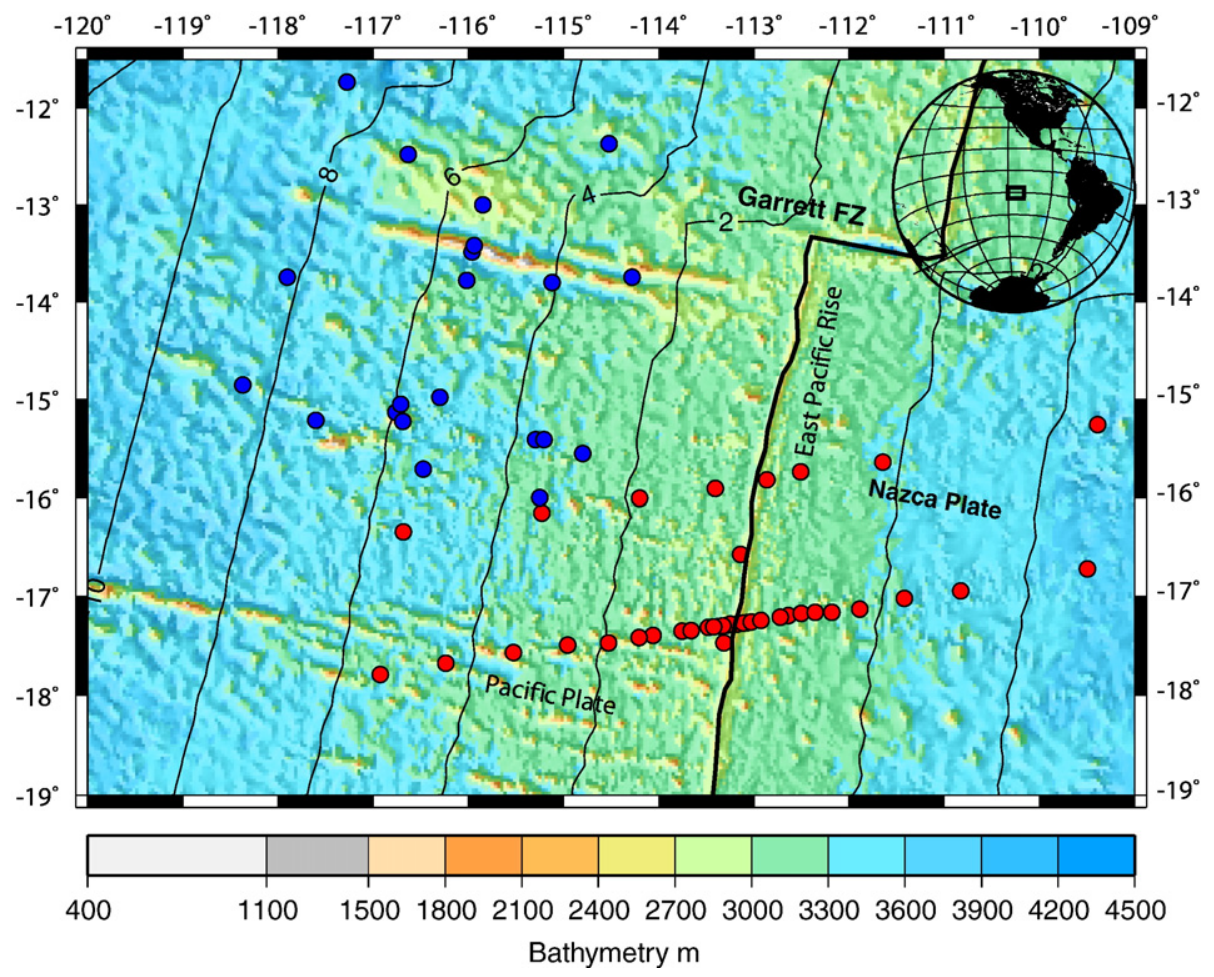

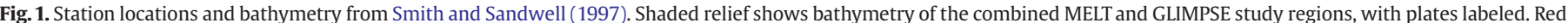

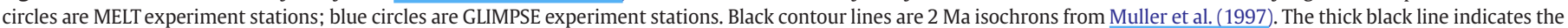

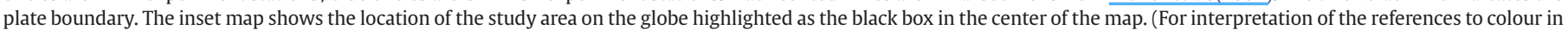
this figure legend, the reader is referred to the web version of this article.) 
least squares inversion to solve for all parameters (Tarantola and Valette, 1982):

$\Delta m_{i}=\left(G^{T} C_{n n}^{-1} G+C_{m m}^{-1}\right)^{-1}\left(G^{T} C_{n n}^{-1} \Delta d+C_{m m}^{-1}\left(m_{i}-m_{0}\right)\right)$

where $m_{i}$ is the current model at iteration $i, \Delta m_{i}$ is the change to the model after the next iteration, $G$ is the matrix of partial derivatives, $C_{n n}$ is data covariance matrix, $C_{m m}$ is the model covariance matrix, $\Delta d$ is the difference between the observed and predicted real and imaginary Fourier coefficients of the Rayleigh wave data, and $m_{0}$ is the starting model. For more details on the method see Forsyth and $\mathrm{Li}$ (2005) and Yang and Forsyth (2006).

The nodes used to parameterize the model are shown in Fig. 2 along with station locations and event-to-station coverage for $22 \mathrm{~s}$ period (period with the greatest number of events, 163 total). To facilitate inversion for velocity as a function of age, the nodes in the array are aligned along isochrons (color coded in Fig. 2). The nodes in the 7th column follow the EPR axis and the nodes on either side are spaced $0.5^{\circ}(\sim 56 \mathrm{~km})$ apart to the east or west for the dense internal node group, while the node spacing increases to $1^{\circ}(\sim 111 \mathrm{~km})$ for the outermost 2 lines of nodes longitudinally and latitudinally. There is an offset in the nodes where the Garrett Fracture Zone offsets the EPR. The outermost nodes are used to help "absorb" the effects of velocity heterogeneities from outside the array that are not adequately represented by the two-plane-wave approximation. These outside nodes are more lightly damped than the inner nodes, achieved by assigning an a priori error that is twice that of the other nodes. The velocities at each node represent coefficients that control the interpolated phase velocities. The actual phase velocity at any point is a Gaussian weighted average of the nodal coefficients in the surrounding area and the characteristic length of the Gaussian function controls the smoothing (Forsyth and Li, 2005). Errors are determined by linearly propagating the full a posteriori covariance matrix of coefficients onto the map (Forsyth and Li, 2005).

The GLIMPSE and MELT data sets are independent in the sense of having no common stations or sources and no overlap of the areas within the arrays, although they do overlap in coverage of seafloor age. The advantage of combining the two data sets in a single inversion is that the resulting phase velocities are better constrained, because each experiment has information about structure outside the array through the broad sensitivity kernels and the rays that cross outside the array. Thus, the adjoining array helps to constrain velocity structure inside the other array. Nevertheless, the overlapping of the regions of sensitivity means that the model structure is not as free to vary as in the inversion of one data set alone; the fit to the data for both arrays is slightly worse than the fit for the individual arrays. We performed both 2-D inversions for lateral variations in velocity at each period and 1-D inversions in which the phase velocities are allowed to vary only with distance from the spreading center. For both sets of inversions, the starting model was the best fitting uniform phase velocity at each period. We show the results of the $1 \mathrm{D}$ inversion here (Fig. 3).

To test the conductive cooling model, we examined two separate isotropic inversions that solved for phase velocity as a function of distance from the EPR. In the first parameterization, we solved for the average velocity in each column of nodes, corresponding to isochrons, thus not constraining the form of the age variation (isochron model). There are a total of 23 parameters in this inversion at each period and

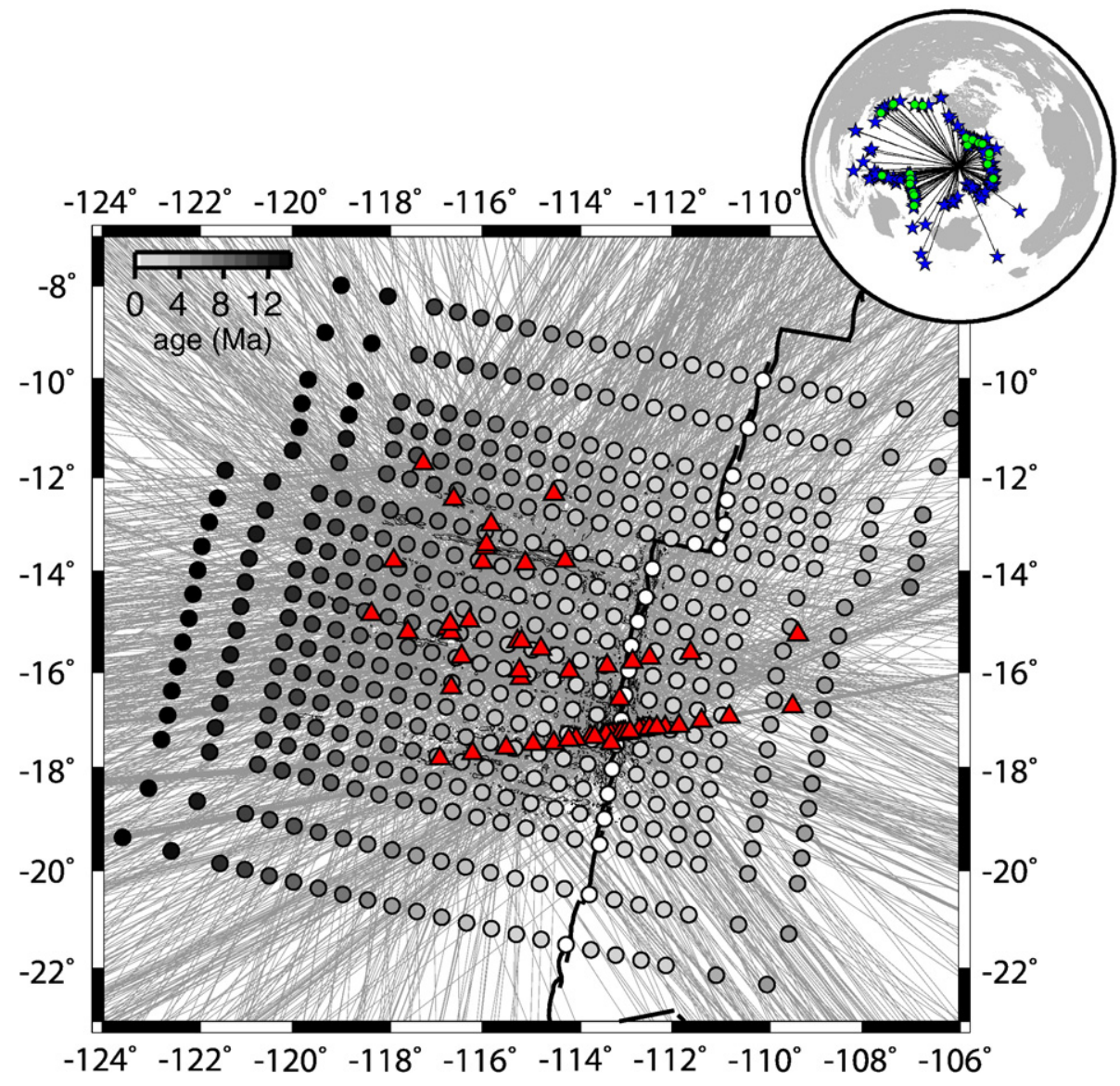

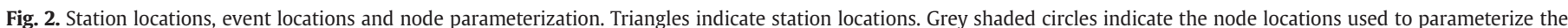

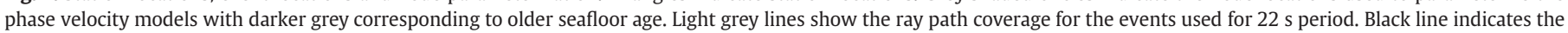

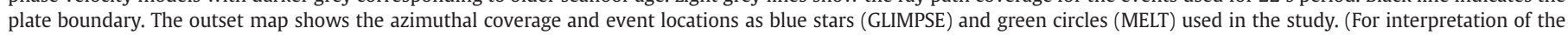
references to colour in this figure legend, the reader is referred to the web version of this article.) 

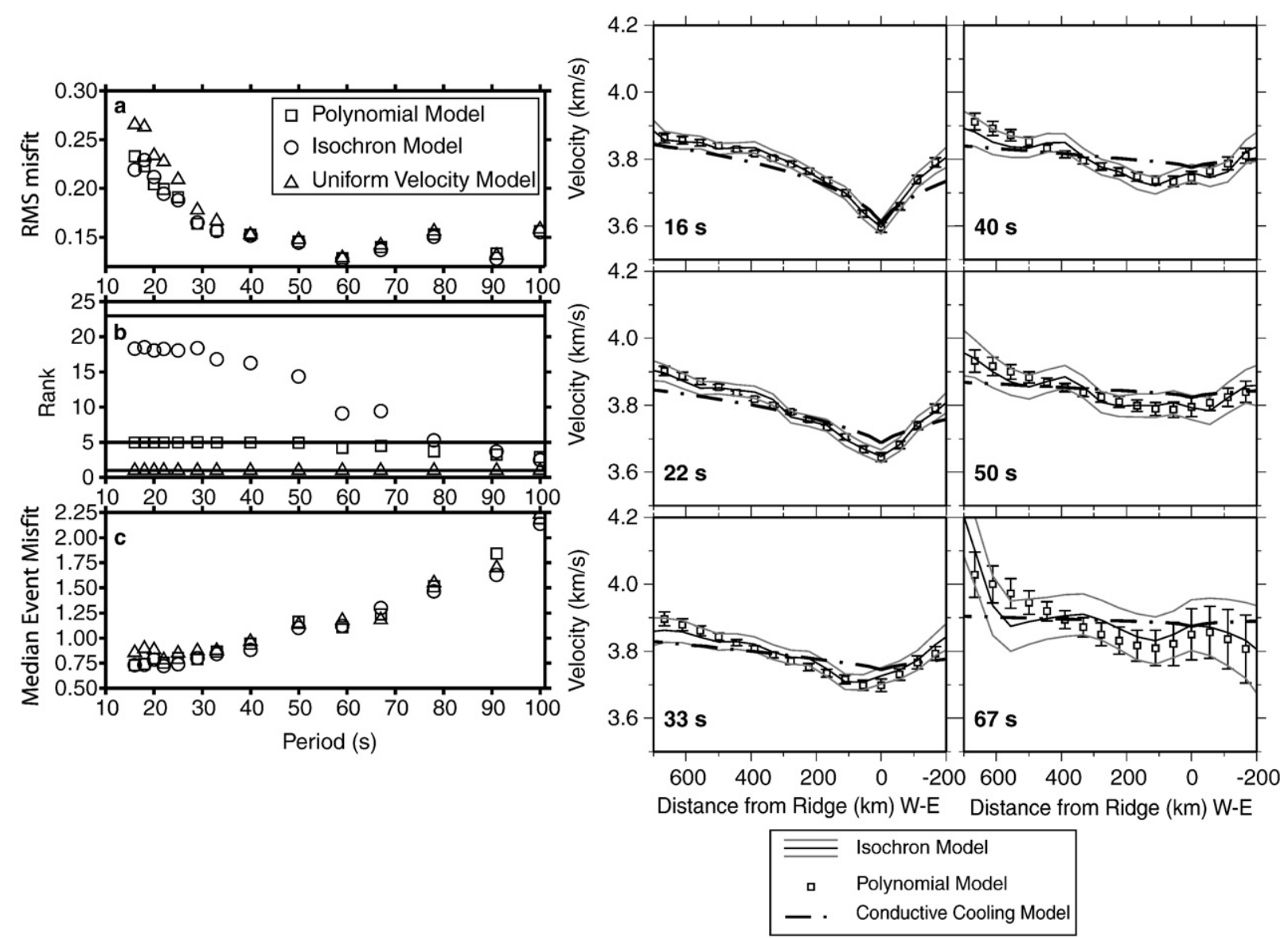

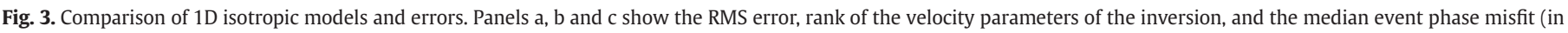

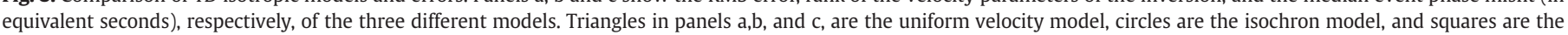

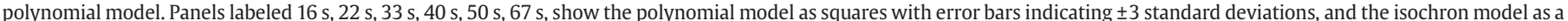

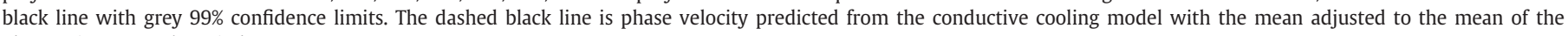
observations at each period.

minimum curvature between values at adjacent nodes was used as the damping or regularization criterion. Specifically, this is achieved by using an a priori inverse model covariance matrix assuming $\lambda=25 \mathrm{~s}^{2}$ / $\mathrm{km}^{2}$ of the form (Press et al., 2002):

$C_{m m}^{-1}=\lambda\left[\begin{array}{ccccccccc}1 & -2 & 1 & 0 & 0 & 0 & 0 & \ldots & 0 \\ -2 & 5 & -4 & 1 & 0 & 0 & 0 & \ldots & 0 \\ 1 & -4 & 6 & -4 & 1 & & & \ldots & 0 \\ 0 & 1 & -4 & 6 & -4 & 1 & & \ldots & 0 \\ \vdots & & & & \ddots & & & & \vdots \\ 0 & \ldots & 0 & 1 & -4 & 6 & -4 & 1 & 0 \\ 0 & \ldots & 0 & 0 & 1 & -4 & 6 & -4 & 1 \\ 0 & \ldots & 0 & 0 & 0 & 1 & -4 & 5 & -2 \\ 0 & \ldots & 0 & 0 & 0 & 0 & 1 & -2 & 1\end{array}\right]$

The second parameterization assumes the phase velocity $\mathrm{c}$ at each period varies as

$c=c_{1}+c_{2} \sqrt{d_{\text {east }}}+c_{3} d_{\text {east }} \quad$ Nazca plate

$c=c_{1}+c_{4} \sqrt{d_{\text {west }}}+c_{5} d_{\text {west }} \quad$ Pacific plate

where $d$ is the distance from the ridge axis east or west and $c_{\mathrm{i}}$ are the polynomial constants. This form was chosen because Rayleigh wave velocities are primarily sensitive to a weighted average of the shear velocity structure as a function of depth, with the depth of penetration increasing with period. If the vertical averaging were uniform, the cooling half-space and plate models would predict variations in phase velocity proportional to the square root of age.
The linear term can represent systematic variations across the arrays; we note that the asymmetry in subsidence of the seafloor in the study area can be accurately represented by a symmetric square root of age variation plus a linear variation continuing across the spreading axis (Conder et al., 2002; Eberle et al., 1998). Note that if either term is not required the coefficient will not be significantly different from zero. We allow for the difference in thermal structure of the Pacific and Nazca plates suggested by asymmetry in subsidence and other physical properties (Cochran, 1986; Conder et al., 2002; Toomey et al., 2002) by allowing a separate square root and linear term for each plate, for a total of 5 parameters at each period with 3 parameters representing the Pacific plate for which we have much better coverage. Due to the inherent smoothness of the polynomial, we use minimum length criteria damping, i.e. no off diagonal terms in $C_{m m}^{-1}$, with diagonals equal to the inverse of the $a$ priori variance, with an a priori damping of $0.2 \mathrm{~km} / \mathrm{s}$.

We evaluate the models in terms of three measures, root-meansquare misfit (RMS misfit), median event misfit and rank of the velocity term in the inversion, after the recommendation of Forsyth and Li (2005). We define the RMS misfit as the misfit of the real and imaginary parts of the Fourier coefficients of the filtered and windowed seismic data to that predicted by our model, where the RMS amplitude of each earthquake has been normalized to 1.0. The RMS misfit is a standard indicator of goodness of fit, but the RMS misfit is sensitive to large outliers produced by a few poorly fit events that were down-weighted in the second set of iterations of the inversion procedure. We define the median event misfit as the median of the RMS phase misfits of each event. Median event misfit provides an 
indicator of how the inversion fits a typical event and may be the most robust indicator of fit. We define the rank here as the sum of the diagonal terms of the resolution matrix corresponding to the velocity model parameters. The rank provides a compact indicator of the number of resolved linear combinations of velocity parameters relative to the total number of velocity parameters. These three metrics provide information of both the goodness of fit to the data and the resolution of the models. The rank and the full resolution matrix allow us to determine if additional independent information is being recovered even if the quality of fit is similar between models.

In a separate set of anisotopic inversions we explore changes in the magnitude of azimuthal anisotropy with age. We assume surface wave phase velocity has azimuthal anisotropy with a fixed fast direction of $100^{\circ}$ azimuth of the form:

$c_{i}={ }_{0} c_{i}+{ }_{1} c_{i}[-0.034 \sin (2 \theta)-0.094 \cos (2 \theta)]$

where $c_{\mathrm{i}}$ are the velocity coefficients for each isochron and $\theta$ is the azimuth of the incoming wave; we neglect higher order azimuthal terms (Smith and Dahlen, 1973). The fixed fast direction approach limits our ability to distinguish between changes in the fast direction of anisotropy and reduction of the magnitude of anisotropy, but it gives us greater sensitivity to changes with distance. Our choice is consistent with the fast direction of SKS splitting measurements (Harmon et al., 2004; Wolfe and Solomon, 1998), previous surface wave studies (Weeraratne et al., 2007), and the spreading direction in the region. In the preliminary set of inversions, we solve for $c_{0}$ and $c_{1}$ for each of the 23 columns of nodes. In this inversion we assume zero anisotropy as a starting model and an a priori error of $0.1 \mathrm{~km} / \mathrm{s}$ for ${ }_{1} c_{\mathrm{i}}$ to provide damping (minimum length criterion). In the second inversion, we remove the damping and re-parameterize the anisotropy magnitude into resolvable age areas using the rank of the anisotropy magnitude results from the first inversion. We present the results of the second inversion here (Fig. 4). We found no significant change in the isotropic ${ }_{0} c_{\mathrm{i}}$ coefficients when the anisotropic coefficients were added, so our lateral changes in velocity are based on the isotropic model.

To invert the phase velocity dispersion for vertical shear velocity structure at each distance from the axis, we use the minimum curvature criterion (Eq. (2)) for an iterative, damped, least squares inversion (Eq. (1)) assuming an a priori model error of $0.2 \mathrm{~km} / \mathrm{s}$. We use the conductive cooling shear velocity model described below as

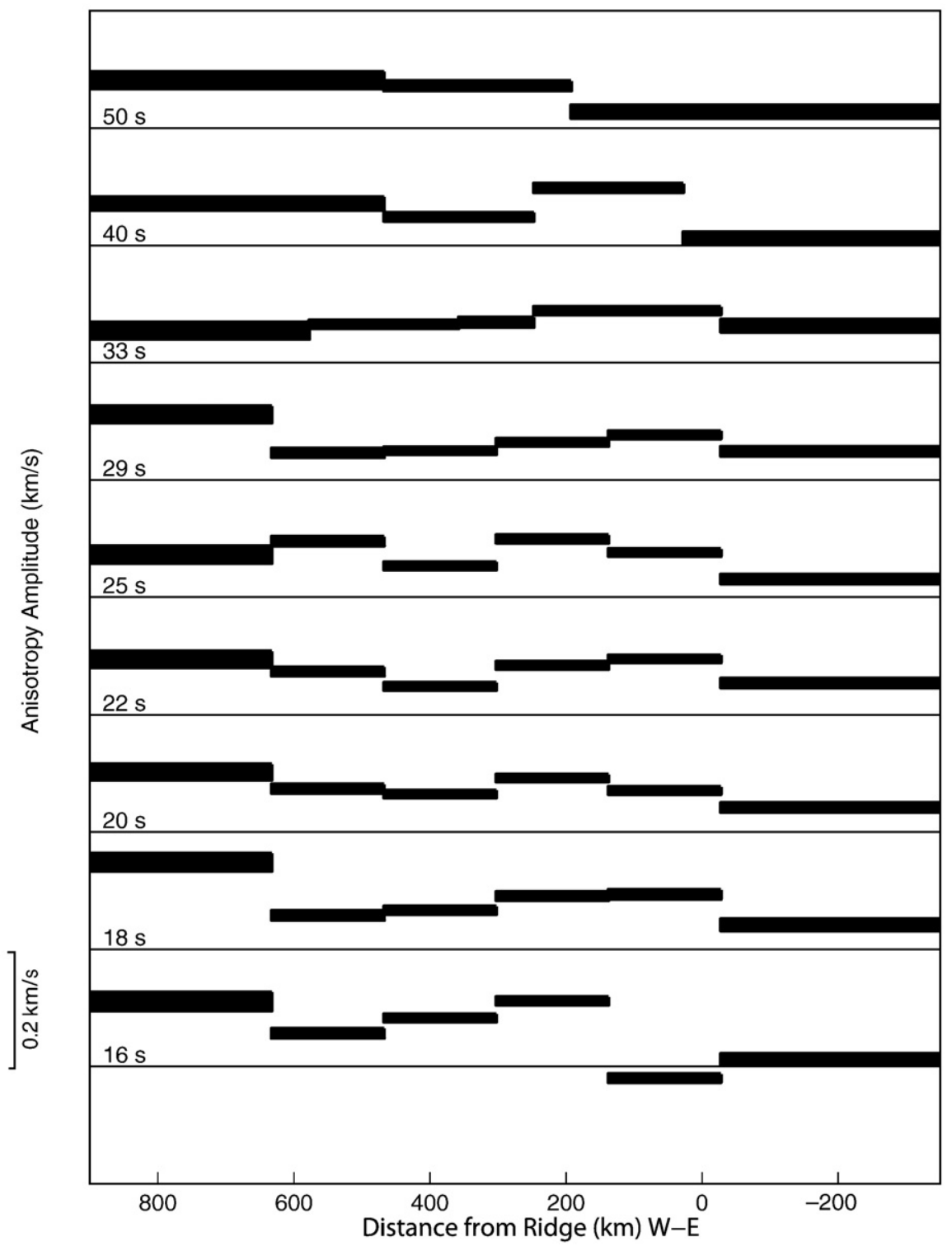

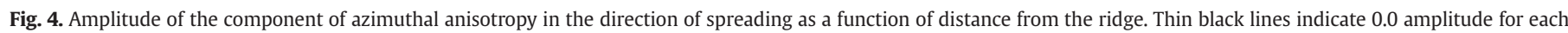
period. Rectangle thickness indicates \pm one standard deviation and length indicates the lateral extent averaged to obtain a well resolved region. 
the starting model for the inversion to minimize differences between the observations and shear velocities expected for the cooling halfspace thermal model. In this model, we assume that water depth varies with distance from the EPR ranging from $3000 \mathrm{~m}$ on axis to $3600 \mathrm{~m}, 800 \mathrm{~km}$ off-axis, with a $6 \mathrm{~km}$ thick, two-layer crust with fixed velocities. We assume $V p / V s=1.78$, but note that $V p$ at depths greater than $20 \mathrm{~km}$ has no significant effect on Rayleigh wave velocities in the period range of our study. We calculate the partial derivatives using DISPER80 (Saito, 1988). The series of 1-D inversions at each distance from the ridge are combined to generate a 2-D cross-sectional model.

\section{Conductive cooling shear velocity model}

We calculate the thermal model assuming the potential temperature in the mantle is $1350^{\circ} \mathrm{C}$ and thermal diffusivity is $8 \times 10^{-7} \mathrm{~m}^{2} \mathrm{~s}^{-1}$. We use a half spreading rate of $72 \mathrm{~mm} / \mathrm{yr}$ to convert age to distance. For comparison to the Rayleigh wave dispersion data and vertically polarized shear velocity, $V_{\mathrm{SV}}$, we convert the thermal model to predicted shear velocity models and calculate the expected phase velocities. After Minster and Anderson (1981), we calculate the anharmonic and anelastic components of the shear velocity, $V_{\mathrm{S}}$, as a function of $P$ and $T$. Specifically we use:

$V_{S}(\omega, T, P)=V_{0}(T, P)\left[1-\frac{1}{2} Q^{-1} \cot \left(\frac{\pi \alpha}{2}\right)\right]$

For the anharmonic velocity, we adopt the approximation of Stixrude and Lithgow-Bertelloni (2005) for peridotite, i.e., $V_{0}(T, P)=$ $4.77+3.80 \times 10^{-11} P-0.000378(T-300)$, with velocity in $\mathrm{km} / \mathrm{s}$, pressure $P$ in Pa and temperature $T$ in ${ }^{\circ} \mathrm{K}$. We note that these coefficients are for isotropic Vs, while Rayleigh waves are sensitive essentially to the equivalent of $V_{\mathrm{SV}}$ for horizontally travelling shear waves. We discuss the implications of polarization anisotropy in Section 5. The attenuation is given by

$Q^{-1}=A\left(\omega \exp \left(\frac{E+P V}{R T}\right)\right)^{-\alpha}$

and we adopt constants that match the attenuation observed for Rayleigh waves in the MELT and GLIMPSE study areas (Yang et al., 2007). Specifically, we choose a value of $A(=0.066)$ that yields $Q=65$ at $150 \mathrm{~km}$ depth, assuming $\alpha=0.1$, the activation energy $E=2.5 \times 10^{5} \mathrm{~J} \mathrm{~mol}^{-1}, R$ is the gas constant, and the activation volume $V=1.0 \times 10^{-5} \mathrm{~m}^{3}$. An observed increase in $Q$ at depths shallower than $70 \mathrm{~km}$ beneath very young seafloor probably reflects the effects of varying water content (Yang et al., 2007), so we reduce $A$ by a factor of 3 between 80 and $50 \mathrm{~km}$ where dehydration is expected to occur during upwelling and melt migration beneath the spreading center. This set of coefficients adequately matches the changes in velocity of Pacific lithosphere and asthenosphere in seafloor older than 20 Ma (Yang et al., 2007). These assumptions lead to a minimum in Vs in our starting model at $80 \mathrm{~km}$ that matches the depth of the minimum found in prior inversions of Rayleigh waves in the GLIMPSE area (Weeraratne et al., 2007; Yang et al., 2007). Using the conductive cooling model shear velocities and assuming $V \mathrm{p} / V \mathrm{~s}=1.78$ to calculate $V \mathrm{p}$, we calculate the model phase velocity dispersion curves every $0.5 \mathrm{Ma}$ from 0 to $10 \mathrm{Ma}$ using DISPER80 (Saito, 1988) and interpolate to distance using the spreading rate.

\section{Age-velocity inversion results}

Panels a, b, and c in Fig. 3 show the RMS misfit, rank and median event misfit of the phase data for the three phase velocity models at each period (the third model is the starting model of the best fitting uniform velocity). For $16-33 \mathrm{~s}$ period, the polynomial model provides an average $20 \%$ reduction in variance of the amplitude and phase data compared to the uniform velocity model (Fig. 3a). The average reduction in variance for the isochron model in this range is $22 \%$, not a significant improvement over the polynomial model considering the number of additional parameters. As discussed in Forsyth and $\mathrm{Li}$ (2005), perhaps the most robust measure of misfit is the median event misfit in phase (Fig. 3c). Between 16 and $33 \mathrm{~s}$, the median event phase misfit for the isochron model is $~ 12 \%$ less than the uniform model, while the isochron and polynomial median misfits are typically within $2 \%$ of each other. The fit to the waveforms improves with increasing period up to about $50 \mathrm{~s}$ (Fig. 3a), but when phase misfit is translated into time (Fig. 3c), the fit worsens and therefore control on velocity weakens. At longer periods, the fit of the isochron and polynomial models are essentially indistinguishable and although there is a resolvable variation in velocity with age at these periods (Fig. 3, right panels), there is only minor improvement in fit relative to the uniform velocity starting model.

The spatial resolution of the models is best summarized by the rank of the inverse problem. Here we describe only the contributions to the rank from the velocity parameters, neglecting the station correction and wavefield parameters. The velocity rank describes how many independent pieces of information about the velocity model are resolvable. For the isochron inversion, 15-18 linearly independent combinations of the 23 model parameters are resolved for periods less than $50 \mathrm{~s}$ (Fig. 3b), including 10 to 15 pieces of information about velocity variations on the Pacific plate alone. This means that in the isochron model 5 to 8 pieces of information are supplied by the $a$ priori starting model assignment of the average velocity with the minimum curvature damping and the rest of the information about the 23 parameters is supplied by the data. Of course, the starting velocity is also based on the data from a prior inversion with only the one constant velocity parameter and there is the usual tradeoff between model variance and model resolution that depends on choice of the damping coefficient. The rank of the polynomial model is $\sim 5$ for periods up to $50 \mathrm{~s}$. At periods greater than $50 \mathrm{~s}$, the rank gradually decreases to $\sim 3$ for both the isochron and polynomial models.

The phase velocities as a function of distance from the axis and period are nearly the same for the polynomial and isochron models, agreeing with each other within their respective $99 \%$ confidence limits at nearly every point (Fig. 3). As the fit to the data is also quite similar, we conclude that the assumed polynomial functional form provides a good, first order representation of the changes in velocity with age. There are small, resolvable differences between the polynomial and isochron models, but the rank of the isochron model indicates that the resolution of average velocity versus distance is on the order of $60 \mathrm{~km}$ and any major deviation from the assumed functional form would have been detected easily.

At periods less than $30 \mathrm{~s}$, the lowest velocities are at the ridge axis (Fig. 3). There is curvature to the velocity-vs.-age trends which is well described by the square root terms. Velocity increases more rapidly to the east of the EPR, in agreement with reports from the MELT Experiment (1998) and the more rapid subsidence of the seafloor on the Nazca plate side (Cochran, 1986; Scheirer et al., 1998). The lowest velocities in the region move off-axis to the west for periods $>30 \mathrm{~s}$. The rank and resolution matrix indicates that these anomalies are resolved. At the longest periods (90-100 s) the polynomial and isochron models are not significantly different from the average velocity, probably due primarily to lack of resolution caused by a decrease in number of useful events, increase in phase error (Fig. 3c) and the increased width of the sensitivity kernel at long periods, and partly to more homogeneity at greater depths.

The lateral velocity gradients in the Rayleigh wave phase velocity models are stronger at periods $\geq 20 \mathrm{~s}$ and $\leq 78 \mathrm{~s}$ than predicted by the conductive cooling model (Fig. 3 ). Above $30 \mathrm{~s}$ period the conductive cooling model predicts essentially no structure in the phase velocities with distance. In contrast, from 33-78 s period, there is a significant increase in phase velocity with increasing distance from the axis on 

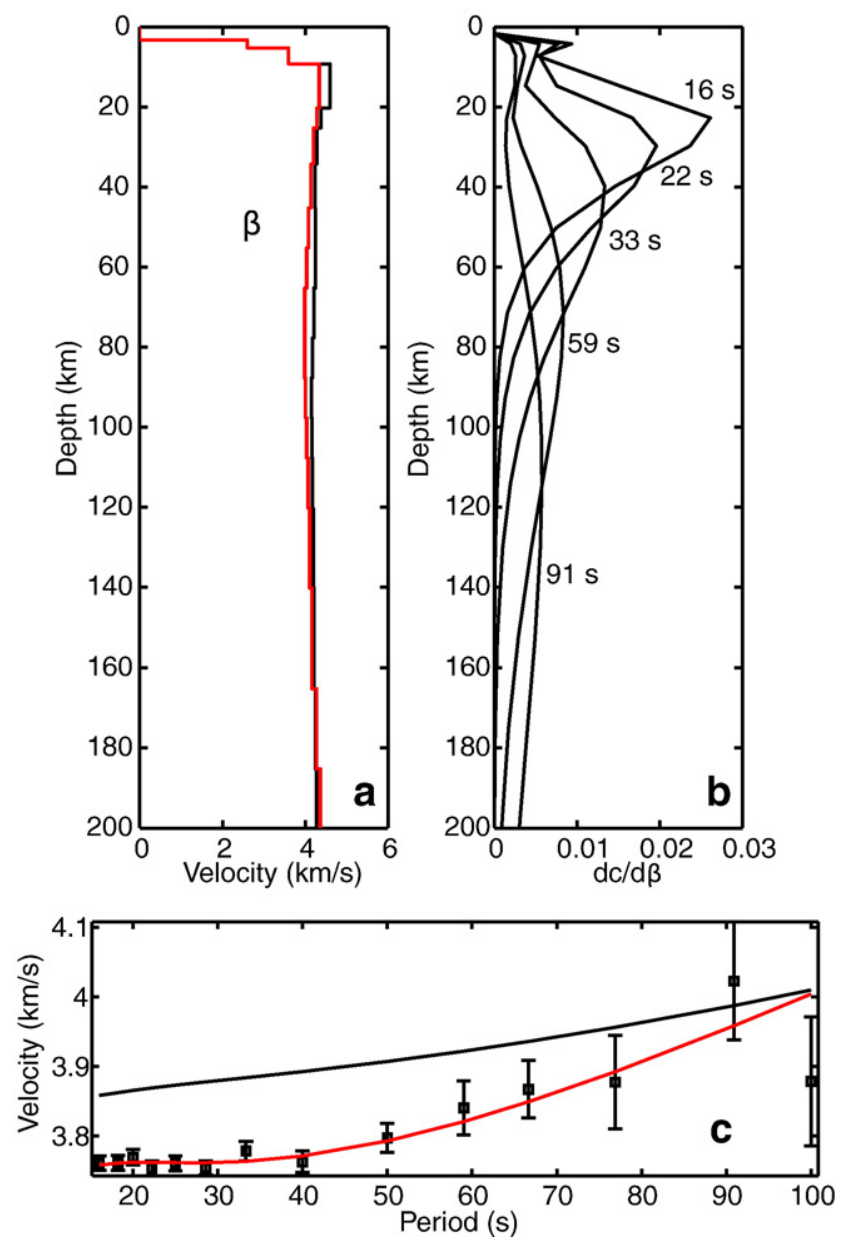

Fig. 5. 1D shear velocity inversion from $\sim 200 \mathrm{~km}$ west of the EPR. (a) Starting (black lines) and final (red lines) shear velocity models. (b) Sensitivity kernels for $16 \mathrm{~s}, 22 \mathrm{~s}, 33 \mathrm{~s}$, $59 \mathrm{~s}$ and $91 \mathrm{~s}$ period. (c) observed (square with error bars) and predicted phase velocities for the final model (red line) and starting model (black line) in (a). (For interpretation of the references to colour in this figure legend, the reader is referred to the web version of this article.)

the Pacific plate. These differences are most prominent at 33-50 s period, where the phase velocity models are significantly lower than the conductive cooling model predictions (not shown in Fig. 3, since the mean velocities are adjusted to agree in the figure) and the lateral variations are much larger than predicted.

The amplitude of azimuthal anisotropy significantly changes with distance from the EPR with two primary features (Fig. 4). First, the anisotropy on the Nazca side of the EPR is significantly smaller on average than the anisotropy on the Pacific plate at all periods. Second, for periods $18-40 \mathrm{~s}$ on the Pacific plate, the average anisotropy is greater $0-300 \mathrm{~km}$ from the axis than in the $300-600 \mathrm{~km}$ distance range. There is a suggestion that the strength of the anisotropy increases again beyond $600 \mathrm{~km}$, but the nominally resolvable region here extends outside the array coverage, so the formal uncertainties may be underestimated. At $50 \mathrm{~s}$ period, the longest period where we can resolve changes in anisotropy, the amplitude decreases from west to east. One other notable feature is that the magnitude of anisotropy on the youngest part of the Pacific plate is small or slightly negative at $16 \mathrm{~s}$ period.

The depth sensitivity of Rayleigh waves to shear velocity broadens and deepens with increasing period (Fig. 5b) and the uncertainties in phase velocities increase with increasing period (Fig. 3), reducing the depth resolution with increasing depth. An example of a 1-D shear velocity inversion for the isochron model at $\sim 200 \mathrm{~km}$ west of the EPR is shown in Fig. 5 along with the depth sensitivity kernels at several periods. The shear velocity models are well resolved, i.e. have a total rank of $\geq 1$ between the depths of $10-45 \mathrm{~km}, 30-75 \mathrm{~km}$ and 60 $150 \mathrm{~km}$, with little information about depths greater than $150 \mathrm{~km}$. Therefore, we only compare the shear velocity models from the isochron and polynomial models to the conductive cooling model in the upper $150 \mathrm{~km}$ of the mantle (Fig. 6). The typical standard error in the shear velocities averaged over these depth ranges is $\sim 0.01 \mathrm{~km} / \mathrm{s}$, however, there can be substantially larger changes to the model within these depth ranges as different model parameters trade off.

The shear velocity cross-sections from the polynomial model (Fig. 6b) and the isochron model (Fig. 6c) have distinct differences from the structure predicted by the conductive cooling model (Fig. 6a). The conductive cooling model predicts velocities in the lithosphere up to a maximum of $4.77 \mathrm{~km} / \mathrm{s}$, and a minimum in the low velocity zone (LVZ) of $4.15 \mathrm{~km} / \mathrm{s}$. The polynomial model produces a maximum velocity of $4.48 \mathrm{~km} / \mathrm{s}$ in the uppermost mantle just below the Moho and a minimum in the low velocity zone of $3.95 \mathrm{~km} / \mathrm{s}$, while the isochron model produces a lithospheric maximum velocity of $4.56 \mathrm{~km} / \mathrm{s}$ in the uppermost mantle and a minimum of $3.93 \mathrm{~km} / \mathrm{s}$. Maxima in the polynomial and isochron models are reached in small regions, while the conductive cooling model predicts uniform high velocities in the uppermost mantle in seafloor older than $1 \mathrm{Ma}$. More important than the maxima are the average velocities over the uppermost $\sim 30 \mathrm{~km}$ that is well resolved, which are systematically $>0.2 \mathrm{~km} / \mathrm{s}$ lower than predicted. The isochron and polynomial models have higher velocities in the uppermost mantle in the Nazca plate than in the Pacific plate of the same age.

All three models exhibit monotonically thickening fast lids with age. On the Nazca Plate, the isochron and polynomial models have a similar structure. On the Pacific plate, the polynomial model has a thicker fast lid than the isochron model, but the isochron model has a
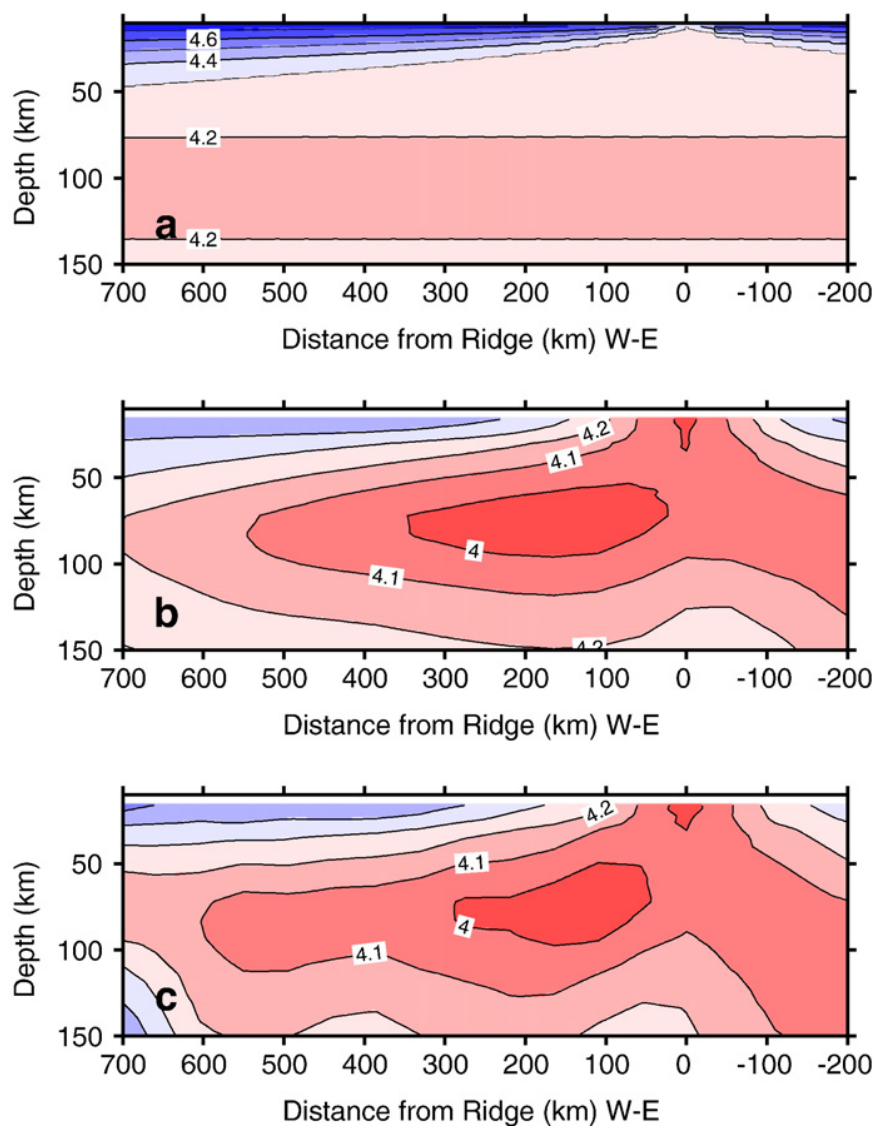

Fig. 6. Shear velocity models from the conductive cooling model (a), polynomial model (b), and the isochron model (c). Positive distance from the ridge is the Pacific plate and negative distance is the Nazca plate. 
higher velocity lid. Given the vertical resolution, these differences are not significant as the vertically averaged velocities over well resolved depth ranges are similar. The conductive cooling model predicts a uniform depth and thickness for the low velocity zone, with the minimum velocity at $\sim 80 \mathrm{~km}$ depth, which is controlled by our assumed attenuation structure, as noted previously. Both the polynomial and isochron models have slightly dipping, asymmetric low velocity zones and a separate, shallow, low velocity region directly beneath the ridge axis. In both models the low velocity zone is shallowest near the ridge axis beneath the Pacific plate and deepens away from the axis, with the depth of the low velocity minimum at $75-90 \mathrm{~km}$ at distances greater than $150 \mathrm{~km}$ from the axis. This LVZ is slightly deeper than reported in Weeraratne et al. (2007) and with a less pronounced minimum. The difference is due to our use of a minimum curvature criterion for model damping instead of the minimum length criterion of that study. The low velocity zone is thicker near the ridge axis and thins away from the axis. In both models the lowest velocities in the low velocity region occur to the west of the axis.

\section{Discussion}

We observe that: 1) the conductive cooling model under predicts the changes with age of the seafloor, particularly within the low velocity zone; 2 ) the conductive cooling model over predicts the shear velocities in the upper $100 \mathrm{~km}$ of the mantle near the ridge; 3 ) the high velocity lithospheric lid is asymmetric, with a thinner plate beneath the Pacific plate than the Nazca plate; 4) the LVZ is asymmetric with the lowest velocities beneath the Pacific plate and with a small, shallow LVZ directly beneath the axis; 5) the LVZ minimum dips to the west beneath the Pacific plate and the lowest velocities are west of the ridge axis; and 6) azimuthal anisotropy is greater on the young Pacific plate than on the Nazca plate, but decreases in amplitude with increasing distance from the axis on the Pacific plate. This mismatch in the structure and magnitude of the shear velocities predicted from the conductive cooling model and the Rayleigh wave phase velocity derived shear velocity model indicate that symmetric passive mantle flow does not completely explain the observations. Therefore additional mechanisms such as anisotropy, higher temperatures, or melt are required to explain the data.

Radial or polarization anisotropy can reduce the differences between our models based on observed phase velocities and the predictions of the conductive cooling model which assumes isotropic $V_{\text {s. }}$ Near the East Pacific Rise, global and regional studies indicate that radial anisotropy is relatively small, on the order of a few percent (Ekstrom, 2000; Nishimura and Forsyth, 1989). Even if we assume the difference between $V_{\mathrm{SH}}$ and $V_{\mathrm{SV}}$ is similar in magnitude to the maximum azimuthal anisotropy of $<5 \%$ in the region (Weeraratne et al., 2007), radial anisotropy can account for less than $0.1 \mathrm{~km} / \mathrm{s}$ of the $>0.2 \mathrm{~km} / \mathrm{s}$ difference we observe in both the lithosphere and the low velocity zone. Specifically, in the uppermost mantle the conductive cooling model predicts shear velocity of $4.77 \mathrm{~km} / \mathrm{s}$ but the maximum velocity in the uppermost mantle from the polynomial and isochron model is $4.48-4.56 \mathrm{~km} / \mathrm{s}$, which is in good agreement with an estimate of $4.50 \mathrm{~km} / \mathrm{s}$ just below the Moho based on short period (2-16 s) fundamental mode and higher mode (3-7 s) Rayleigh waves (Harmon et al., 2007a,b). Note that the starting model for the shear velocity inversion is the conductive cooling model which has high velocities just beneath the Moho. Although vertical resolution is limited, this feature will not disappear unless required by the Rayleigh wave data. We conclude that there is a significant difference between the predicted velocities and the observed velocities that is not simply due to polarization anisotropy or lack of resolution.

Another concern is that lateral changes in polarization anisotropy could cause the apparent lateral changes in $V_{\mathrm{SV}}$ we observe at depths greater than where conductive cooling is expected to have any effect.
At depths of about $80 \mathrm{~km}$, there is an increase beneath the Pacific plate of about $0.2 \mathrm{~km} / \mathrm{s}$ with increasing distance from the ridge axis (Fig. 6). As explained above, this is too large a change to be due to the difference between isotropic $V_{\mathrm{S}}$ and $V_{\mathrm{SV}}$. In addition, regional and global studies indicate that $V_{\mathrm{SH}} / V_{\mathrm{SV}}$ increases with increasing distance from the East Pacific Rise on the Pacific plate (Ekstrom, 2000; Nishimura and Forsyth, 1989), which would cause a decrease in $V_{\mathrm{SV}}$, not an increase, if the change in polarization anisotropy is caused by increased horizontal alignment of olivine $a$-axes. We found in this study a small decrease $(<1 \%)$ in average azimuthal anisotropy beneath the Pacific plate from 0-300 km from the axis to $300-600 \mathrm{~km}$, a change far too small to have a significant effect on the lateral changes in velocity, There is little local control on $V_{\mathrm{SH}} / V_{\mathrm{SV}}$ because tilting of the OBSs due to bottom currents severely limits the number of Love waves that can be observed at long periods. Dunn and Forsyth (2003) presented an image of $V_{\mathrm{SH}}$ based on short period (4-17 s) Love waves recorded in the MELT Experiment, but good resolution was limited to the upper $50 \mathrm{~km}$ within $100 \mathrm{~km}$ of the spreading center. They found the lowest velocities immediately beneath the Moho at the spreading center with asymmetry increasing downwards, similar to the pattern found in this study. Although the spatial resolution in the two studies is much different, comparison of the models suggests that $V_{\mathrm{SH}}$ is $1-3 \%$ faster than $V_{\mathrm{SV}}$ in the shallow, near-axis mantle.

One possible reason that the conductive cooling model is faster than our inverted models in the upper $60 \mathrm{~km}$ is our use of the Stixrude and Lithgow-Bertelloni (2005) velocity prediction for garnet peridotite throughout the model. There is of course some uncertainty in their prediction; they estimate $\sim 1.3 \%$ or $0.06 \mathrm{~km} / \mathrm{s}$, too small to explain the discrepancy. Yet, they show that there should be a small drop in shear velocity $(\sim 0.02 \mathrm{~km} / \mathrm{s})$ at the garnet to spinel peridotite transition, because the atomic fraction of orthopyroxene increases at the same time. They show a larger decrease in velocity with the transition to plagioclase peridotite in the very shallow mantle, but this decrease probably never occurs because the depletion of peridotite during the partial melting process beneath the ridge leaves a residual lithosphere in which plagioclase never forms.

One physical reason why the uppermost mantle might be slower than expected is that hydrothermal alteration both on and off-axis may serpentinize the olivine-rich uppermost mantle and effectively reduce the seismic velocity. Approximately 9\% serpentinization of mantle peridotite could produce $\sim 0.2 \mathrm{~km} / \mathrm{s}$ reduction in velocity (Christensen, 1966; Horen et al., 1996). This is a reasonable estimate for the upper mantle, considering that mantle peridotites have a broad range of serpentinization (Christensen, 1966; Horen et al., 1996).

The discrepancy in the minimum shear velocities in the LVZ between the conductive cooling shear velocity model and the surface wave shear velocity models may be partly explained by higher temperatures in the mantle, particularly beneath the Pacific plate. More than $200{ }^{\circ} \mathrm{C}$ increase in temperature is required to bring the prediction of the conductive cooling model into agreement with the observed shear velocity models, even if we make a maximum correction of $0.1 \mathrm{~km} / \mathrm{s}$ for the effect of radial anisotropy and allow for error in the conductive cooling model itself. This is a large thermal anomaly. By analogy to back arc basin shear velocities and mantle potential temperatures determined from dry MORB-like samples, a temperature range of $1350-1450{ }^{\circ} \mathrm{C}$ seems more likely (Wiens et al., 2006). Regionally, Cochran (1986) estimated a lateral temperature increase of $100{ }^{\circ} \mathrm{C}$ beneath the Pacific plate across the EPR in the upper mantle to explain the slower subsidence of the Pacific plate relative to the Nazca plate. If we presume there is a $\sim 100{ }^{\circ} \mathrm{C}$ temperature increase beneath the Pacific plate, then another mechanism such as melt is needed to fully explain the low shear velocities.

Melt may affect the absolute shear velocity due to poroelastic effects, i.e., lowering the aggregate velocity by adding a lower velocity phase to the mineral assemblage. Hammond and Humphreys (2000) estimated a $7.9 \%$ reduction in $V_{\mathrm{S}}$ for $1 \%$ melt in realistic geometries. 
Assuming a linear dependence of $V_{\mathrm{S}}$ on melt content for porosity below $1 \%, \sim 0.3 \%$ melt would be required to produce a $0.1 \mathrm{~km} / \mathrm{s}$ velocity reduction. Although the geometry of melt distribution on which the Hammond and Humphreys estimate is based has been challenged (Wark et al., 2003), disequilibrium melt distribution produced during recrystallization (Waite et al., 2003) or localization of melt into bands during deformation (Holtzman et al., 2003) could produce the flat melt pockets needed to strongly affect shear velocities with only small melt concentrations (Schmeling, 1985).

The asymmetric lithospheric velocity structure and low velocity zone structure is coincident with asymmetric off-axis surface volcanism (Scheirer et al., 1998). The volcanism is distributed along strike of the EPR in the study area in three sets of linear seamount chains or volcanic ridges that form off-axis on the Pacific plate, trending in the direction of absolute plate motion (Forsyth et al., 2006; Sandwell et al., 1995). The off-axis magma production in the MELT and GLIMPSE study region is estimated to be 1 to $2 \%$ of the total crustal production at the EPR (Harmon et al., 2006; Shen et al., 1993), generating ridge systems thousands of $\mathrm{km}$ long and rising to within a few hundred meters of the sea surface (Forsyth et al., 2006; Sandwell et al., 1995). Off-axis volcanism in the region has occurred as recently as $0.16 \mathrm{Ma}$ on $6 \mathrm{Ma}$ seafloor from ${ }^{39} \mathrm{Ar} /{ }^{40} \mathrm{Ar}$ age dating (Forsyth et al., 2006). Recent volcanism $(<1 \mathrm{Ma})$ is also inferred from seafloor roughness on younger Pacific seafloor, the freshness of dredged basalts, and microseismic activity beneath Matua seamount (Forsyth et al., 2006). Thus there is evidence that there is off-axis volcanism occurring today, and that the seismic "snapshot" presented here could reflect the presence of higher temperatures and melt in an active magmatic system.

The shallow LVZ is also coincident with the depths predicted for incipient dry melting of mantle peridotite with potential temperatures of $1340-1400{ }^{\circ} \mathrm{C}$ (Katz et al., 2003). To explain the asymmetry of structure and the large lateral extent of very low shear velocities beneath the Pacific plate, Conder et al. (2002) and Toomey et al. (2002), created numerical simulations of mantle flow and temperature in which return flow to the East Pacific Rise comes from the Pacific superswell region to the west, carrying anomalously hot material in the asthenosphere to the ridge axis. The models can generate an asymmetric melt region that extends $>200 \mathrm{~km}$ west of the EPR and deepens away from the axis, matching the asymmetry in body wave delay times and subsidence (Toomey et al., 2002) and the asymmetry in SKS splitting times across the EPR (Blackman and Kendall, 2002), in addition to explaining the features we observe from surface wave tomography.

A major remaining question is why the lowest velocities at asthenospheric depths of 60 to $100 \mathrm{~km}$ are not found directly beneath the ridge axis (Fig. 6c). Possible contributing factors include more efficient melt extraction beneath the ridge, more vertical orientation of the olivine a-axis, and lateral averaging of a highly asymmetric structure. The "plumbing" system may be better established beneath the spreading center, whereas off-axis, more of the melt may be trapped beneath the thickening, cooling lithosphere. If the olivine $a$ axis is more vertical beneath the ridge axis due to the upwelling flow, as has often been suggested, then under the same pressure and temperature conditions, the azimuthally-averaged Rayleigh wave velocity would increase somewhat in comparison to the dominantly horizontal orientation expected off-axis. Our observational constraints on azimuthal or polarization anisotropy at these depths beneath the ridge axis are weak; a change to a more vertical axis is allowed, but there is little positive indication of it. Finally, if the melting region ends abruptly at the ridge axis and is largely absent beneath the Nazca plate, as suggested by some of the models involving across-axis flow from the Pacific superswell (Conder et al., 2002), then lateral averaging could increase the apparent velocity at the transition between the two regimes directly beneath the axis. We note that lateral averaging increases with depth as the rank or information content of the Rayleigh wave inversion decreases with increasing period (Fig. 3b).

The azimuthal anisotropy of the Rayleigh waves and SKS splitting measurements in the region are generally consistent with each other, but not with the simple predictions of an advective, plate spreading model. Wolfe and Solomon (1998) showed that the splitting delay time between the fast and slow directions off-axis on the Nazca plate is $\sim 1 \mathrm{~s}$, while off-axis splitting for the MELT stations on the Pacific plate is $\sim 2 \mathrm{~s}$; the azimuthal anisotropy we observe here has the same average ratio for $18-33 \mathrm{~s}$ periods from $0-300 \mathrm{~km}$ from the ridge. Further off-axis, $>5 \mathrm{Ma}$ or $>350 \mathrm{~km}$ away the EPR on the Pacific plate, the SKS splitting measurements drop down to $\sim 1 \mathrm{~s}$ (Harmon et al., 2004), and we observe the amplitude of the Rayleigh wave anisotropy on the Pacific plate $300-600 \mathrm{~km}$ from the axis drops to approximately the same average value as the Nazca plate. There is no reason to expect the lattice-preferred orientation of olivine and enstatite to decrease with increasing age in simple, 2D, mantle flow models (Blackman and Kendall, 2002). Rather, we might expect the strength of anisotropy to increase since more strain in the spreading direction is expected to accumulate over time away from the ridge axis.

Three possible interpretations of the variations of the magnitude of azimuthal anisotropy in the region are: the mode of anisotropy changes, the direction of olivine alignment changes, or the strength or depth extent of the alignment changes. The small or negative amplitude observed at $16 \mathrm{~s}$ period near the EPR on the Pacific plate (Fig. 4) suggests that there may be melt filled cracks at shallow depths aligned in the trend of the EPR, which would tend to make the fast direction of propagation ridge parallel. Combining the effects of melt orientation and olivine fabric with a fast axis perpendicular to the ridge could lead to a near-null result. An alternate explanation is that near the surface at the ridge no strong olivine fabric has developed. Forsyth et al. (1998) suggested that the presence of melt beneath the axis could enhance diffusion creep to the point that it is the dominant deformation mechanism, in which case no substantial latticepreferred orientation (LPO) or anisotropy would be expected (Hirth and Kohlstedt, 1995). Vertical alignment of the olivine $a$-axis would also produce near-zero azimuthal anisotropy of Rayleigh waves. These latter two explanations seem unlikely, because the null effect is observed only at the shortest period in this study. Previous modeling with less data that did not employ Born approximation finitefrequency kernels reported that the axial minimum existed across a much broader range of periods (Forsyth et al., 1998).

Conder (2007) has shown that the contrast in splitting and anisotropy between the Pacific and Nazca plates can be explained by dynamically driven mantle flow from west to east across the EPR. Higher strain rates beneath the Pacific plate in that model lead to greater dominance of dislocation creep over diffusion creep, increased LPO, and a thicker anisotropic layer. However, it is difficult to explain the decrease in anisotropy at distances greater than $300 \mathrm{~km}$ from the ridge axis in the Pacific plate with the $2 \mathrm{D}$ flow models proposed to date. Perhaps the best explanation may be the onset or increasing influence of 3D flow that may be responsible for the formation of the gravity lineaments, seamount chains and underlying mantle structure on the Pacific plate (Harmon et al., 2007a,b; Haxby and Weissel, 1986; Weeraratne et al., 2007). Small scale convection (Buck and Parmentier, 1986) could disrupt the simple 2D pattern associated with the spreading and return flow.

\section{Conclusions}

We measure the change in Rayleigh wave phase velocities with seafloor age for the EPR near $17^{\circ} \mathrm{S}$ with much greater resolution than achieved in previous studies. The 16-33 s period Rayleigh wave phase velocities show a strong square root of seafloor age dependence, indicating that conductive cooling plays an important role in developing the seismically fast lid in the oceans. However, the 
conductive cooling shear velocity model presented here, which includes anelastic and anharmonic affects, under predicts the changes in phase velocity with age, over predicts the absolute values of shear velocity and does not predict the asymmetry across the EPR, the changes with age in the asthenosphere below the high velocity lid, or the minimum in velocities to the west of the EPR. An asthenospheric thermal anomaly, melt and dynamically driven flow are needed to explain these shear velocity anomalies. The decrease in magnitude of azimuthal anisotropy on older Pacific seafloor, in conjunction with the presumed melting and thermal anomalies suggest 3D mantle flows such as small-scale convection are at work beneath the Pacific plate.

\section{References}

Blackman, D.K., Kendall, J.M., 2002. Seismic Anisotropy in the upper mantle, 2. Predictions for current plate boundary flow models. Geochem. Geophys. Geosys. 3 , $1-26$.

Buck, W.R., Parmentier, E.M., 1986. Convection beneath young oceanic lithosphere: implications for thermal structure and gravity. J. Geophys. Res. 91, 1961-1974.

Christensen, N.I., 1966. Elasticity of ultrabasic rocks. J. Geophys. Res. 71, 5921-5931.

Cochran, J.R., 1986. Variations in subsidence rates along intermediate and fast spreading mid-ocean ridges. Geophys. J. R. Astron. Soc. 87, 421-454.

Collins, J.A., Vernon, F.L., Orcutt, J.A., Stephen, R.A., 2002. Upper mantle structure beneath the Hawaiian Swell: constraints from the ocean seismic network pilot experiment. Geophys. Res. Lett. 29. doi:10.1029/2001GL013302.

Conder, J.A., 2007. Dynamically driven mantle flow and shear wave splitting asymmetry across the EPR, MELT area. Geophys. Res. Lett. L16301. doi:10.1029/2007GL030832

Conder, J.A., Forsyth, D.W., Parmentier, E.M., 2002. Asthenospheric flow and asymmetry of the East Pacific Rise. J. Geophys. Res. 107, 2344.

Courtier, A.M., Bagley, B., Revenaugh, I., 2007. Whole mantle discontinuity structure beneath Hawaii. Geophys. Res. Lett. 34, L17304. doi:10.1029/2007GL031006.

Dunn, R.A., Forsyth, D.W., 2003. Imaging the transition between the region of mantle melt generation and the crustal magma chamber beneath the southern East Pacific Rise with short-period Love waves. J. Geophys. Res. 108, 2352. doi:10.1029/ 2002]B002217.

Eberle, M.A., Forsyth, D.W., Parmentier, E.M., 1998. Constraints on a buoyant model for the formation of the axial topographic high on the East Pacific Rise. J. Geophys. Res, 103, 12291-12307.

Ekstrom, G., 2000. Mapping the lithosphere and asthenosphere with surface waves: lateral structure and anisotropy. In: Richards, M.A., Gordon, R.G., Van der Hilst, R.D. (Eds.), The History and Dynamics of Global Plate Motions, Geophyiscal Monograph Series. Geophysical Monograph, vol. 121. American Geophysical Union, pp. 239-255.

Evans, R.L., Hirth, G., Baba, K., Forsyth, D., Chave, A., Mackie, R., 2005. Geophysical evidence from the MELT area for compositional controls on oceanic plates. Nature 437, 249-252.

Evans, R.L., Tarits, P., Chave, A.D., White, A., Heinson, G., Filloux, J.H., Toh, H., Seama, N., Utada, H., Booker, I.R., Unsworth, M.I., 1999. Asymmetric electrical structure in the mantle beneath the East Pacific Rise at $17^{\circ}$ S. Science 286, 752-756.

Faul, U.H., Jackson, I., 2005. The seismologic signature of temperature and grain size variations in the upper mantle. Earth Planet. Sci. Lett. 234, 119-134.

Forsyth, D.W., 1975. The early structural evolution and anisotropy of the oceanic upper mantle. Geophys. J. R. Astron. Soc. 43, 103-162.

Forsyth, D.W., 1977. Evolution of upper mantle beneath mid-ocean ridges. Tectonophysics 38, 89-118.

Forsyth, D.W., Harmon, N., Scheirer, D.S., Duncan, R.A., 2006. Distribution of recent volcanism and the morphology of seamounts and ridges in the GLIMPSE study area: implications for the lithospheric cracking hypothesis for the origin of intraplate non hotspot volcanic chains. J. Geophys. Res. 111, B11407. doi:10.1029/2005JB004075.

Forsyth, D.W., Li, A., 2005. Array-analysis of two-dimensional variations in surface wave phase velocity and azimuthal anisotropy in the presence of multipathing interference. In: Levander, A., Nolet, G. (Eds.), Seismic Data Analysis and Imaging with Global and Local Arrays. AGU Geophysical Monograph. AGU Monograph.

Forsyth, D.W., Scheirer, D.S., Webb, S.C., Dorman, L.M., Orcutt, J.A., Harding, A.J., Blackman, D.K., Phipps, M.J., Detrick, R.S., Shen, Y., Wolfe, C.J., Canales, J.P., Toomey, D.R., Sheehan, A.F., Solomon, S.C., Wilcock, W.S.D., Melt Seismic Team, U.S., 1998. Imaging the deep seismic structure beneath a mid-ocean ridge; the MELT experiment. Science $280,1215-1218$

Gaherty, J.B., Jordan, T.H., Gee, L.S., 1996. Seismic structure of the upper mantle in a central Pacific corridor. J. Geophys. Res. 101, 22,291-222,309.

Hammond, W.C., Humphreys, E.D., 2000. Upper mantle seismic wave attenuation: effects of realistic partial melt distribution. J. Geophys. Res. 105, 10987-10999.

Hammond, W.C., Toomey, D.R., 2003. Seismic velocity anisotropy and heterogeneity beneath the Mantle Electromagnetic and Tomography Experiment (MELT) region of the East Pacific Rise from analysis of P and S body waves. J. Geophys. Res. 108, 2176 doi:10.1029/2002JB001789.

Harmon, N., Forsyth, D.W., Fischer, K.M., Webb, S.C., 2004. Variations in shear-wave splitting in young Pacific seafloor. Geophys. Res. Lett. 31. doi:10.1029 2004GL020495.

Harmon, N., Forsyth, D.W., Scheirer, D.S., 2006. Analysis of gravity and topography in the GLIMPSE study region: isostatic compensation and uplift of the Sojourn and Hotu Matua Ridge systems. J. Geophys. Res. 111, B11406. doi:10.1029/2005]B004071.
Harmon, N., Forsyth, D.W., Lamm, R., Webb, S., 2007a. P and S delays beneath intraplate volcanic ridges and gravity lineations near the East Pacific Rise. J. Geophys. Res. 112. doi:10.1029/2006JB004392.

Harmon, N., Forsyth, D., Webb, S., 2007b. Using ambient seismic noise to determine short-period phase velocities and shallow shear velocities in young Oceanic Lithosphere Bull. Seis. Soc. Am. 97, 2024-2039.

Haxby, W.F., Weissel, J.K., 1986. Evidence for small-scale mantle convection from Seasat altimeter data. J. Geophys. Res. 91, 3507-3520.

Hirth, G., Kohlstedt, D.L., 1995. Experimental constraints on the dynamics of the partially molten upper-mantle 2. Deformation in the dislocation creep regime. J. Geophys. Res. 100, 15441-15449.

Holtzman, B.K., Kohlstedt, D.L., Zimmerman, M.E., Heidelbach, F., Hiraga, T., Hustoft, J., 2003. Melt segregation and strain partitioning: implications for seismic anisotropy and mantle flow. Science 301, 1227-1230.

Horen, H., Zamora, M., Dunuisson, 1996. Seismic waves velocities and anisotropy in serpentinized peridotites from Xigaze ophiolite: abundance of serpentine in slow spreading ridge. Geophys. Res. Lett. 23, 9-12.

Katz, R.F., Spiegelman, M., Langmuir, C.H., 2003. A new parameterization of hydrous mantle melting. Geochem. Geophys. Geosys. 4, 1073. doi:10.1029/2002GC000433.

Kausel, E.G., Leeds, A.R., Knopoff, L., 1974. Variations of Rayleigh-wave phase velocities across Pacific Ocean. Science 186, 139-141.

Key, K., Constable, S., 2008. Ridge Migration produces deep asymmetric mantle melting at the northern East Pacific Rise. Submitted to Nature.

Li, X., Kind, R., Yuan, X., Wolbern, I., Hanka, W., 2004. Rejuvenation of the lithosphere by the Hawaiian Plume. Nature (London). 427, 827-829.

Maggi, A., Debayle, E., Priestley, K., Barruol, G., 2006. Azimuthal anisotropy of the Pacific region. Earth Planet. Sci. Lett. 250, 53-71.

Mckenzie, D.P., 1967. Some remarks on heat flow and gravity anomalies. J. Geophys. Res. 72, 6261-6273.

Minster, J.B., Anderson, D.L., 1981. A model of dislocation-controlled rheology for the mantle. Philos. Trans. R. Soc. London 299, 319-356.

Muller, R.D., Roest, W.R., Royer, J.Y., Gahagan, L.M., Sclater, J.G., 1997. Digital isochrons of the world's ocean floor. J. Geophys. Res. 102, 3211-3214.

Nishimura, C.E., Forsyth, D.W., 1988. Rayleigh-wave phase velocities in the Pacific with implications for azimuthal anisotropy and lateral heterogeneities. Geophys. J. Int. 94, 479-501.

Nishimura, C.E., Forsyth, D.W., 1989. The anisotropic structure of the upper mantle in the Pacific. Geophys. J. Int. 96, 203-229.

Parker, R.L., Oldenburg, D.W., 1973. Thermal model of ocean ridges. Nat. Phys. Sci. 242, $137-139$.

Parsons, B., Sclater, J.G., 1977. Analysis of variation of ocean-floor bathymetry and heatflow with age. J. Geophys. Res. 82, 803-827.

Press, W.H., Teukolsky, S.A., Vetterling, W.T., Flannery, B.P., 2002. Numerical Recipes in C+: The Art of Scientific Computing. Cambridge University Press, Cambridge.

Priestley, K., McKenzie, D., 2006. The thermal structure of the lithosphere from shear wave velocities. Earth Planet. Sci. Lett. 244, 285-301.

Revenaugh, J., Jordan, T.H., 1991. Mantle layering from Scs reverberations 3. The upper mantle. J. Geophys. Res. 96, 19781-19810.

Ritzwoller, M.H., Shapiro, N.M., Zhong, S.J., 2004. Cooling history of the Pacific lithosphere. Earth Planet. Sci. Lett. 226, 69-84.

Saito, M., 1988. DISPER80: a subroutine package for the calculation of seismic normalmode solutions. In: Doornbos, D.J. (Ed.), Seismological Algorithms: Computational Methods and Computer Programs. Academic Press, San Diego, pp. 293-319.

Sandwell, D.T., Winterer, E.L., Mammerickx, I., Duncan, R.A., Lynch, M.A., Levitt, D.A., Johnson, C.L., 1995. Evidence for diffuse extension of the Pacific Plate from Pukapuka ridges and cross-grain gravity lineations. J. Geophys. Res. 100, 15,087-015,099.

Scheirer, D.S., Forsyth, D.W., Cormier, M.H., Macdonald, K.C., 1998. Shipboard geological indications of asymmetry and melt production beneath the East Pacific Rise near the MELT experiment. Science 280, 1221-1224.

Schmeling, H., 1985. Partial melt below Iceland-a combined interpretation of seismic and conductivity data. J. Geophys. Res. 90, 105-116.

Shen, Y., Forsyth, D.W., Scheirer, D.S., Macdonald, K.C., 1993. Two forms of volcanism; implications for mantle flow and off-axis crustal production on the west flank of the southern East Pacific Rise. J. Geophys. Res. 98, 17,875-817,889.

Smith, M.L., Dahlen, F.A., 1973. Azimuthal dependence of Love and Rayleigh-wave propagation in a slightly anisotropic medium. J. Geophys. Res. 78, 3321-3333.

Smith, W.H.F., Sandwell, D.T., 1997. Global seafloor topography from satellite altimetry and ship soundings. Science 277, 1957-1962.

Stein, S., Stein, C.A., 1992. A model for the global variation in oceanic depth and heat flow with lithospheric age. Nature 359, 123-129.

Stixrude, L., Lithgow-Bertelloni, C., 2005. Mineralogy and elasticity of the oceanic upper mantle: origin of the low-velocity zone. J. Geophys. Res. 110, B03204. doi:10.1029/ 2004JB002965.

Tan, Y., Helmberger, D.V., 2007. Trans-Pacific upper mantle shear velocity structure. J. Geophys. Res. 112, B08301. doi:10.1029/2006JB004853.

Tarantola, A., Valette, B., 1982. Generalized nonlinear inverse problems solved using the least squares criterion. Rev. Geophys. Space Phys. 20, 219-232.

Toomey, D.R., Wilcock, W.S., Solomon, S.C., Hammond, W.C., Orcutt, J.A., 1998. Mantle seismic structure beneath the MELT region of the east Pacific Rise from P and S wave tomography. Science 280, 1224-1227.

Toomey, D.R., Wilcock, W.S.D., Conder, J.A., Forsyth, D.W., Blundy, J.D., Parmentier, E.M., Hammond, W.C., 2002. Asymmetric mantle dynamics in the MELT region of the East Pacific Rise. Earth Planet. Sci. Lett. 200, 287-295.

Toomey, D.R., Jousselin, D., Dunn, R.A., Wilcock, W.S.D., Detrick, R.S., 2007. Skew of mantle upwelling beneath the East Pacific Rise governs segmentation. Nature 446, 409-414. 
Vinnik, L.P., Foulger, G.R., Du, Z., 2005. Seismic boundaries in the mantle beneath Iceland: a new constraint on temperature. Geophys. J. Int. 160, 533-538.

Waite, N.P., Bons, P.D., Passchier, C.W., Koehn, D., 2003. Disequilibrium melt distribution during static recrystallization. Geology 31, 1009-1012.

Wark, D.A., Williams, C.A., Watson, E.B., Price, J.D., 2003. Reassessment of pore shapes in microstructurally equilibrated rocks, with implications for permeability of the upper mantle. J. Geophys. Res. 108, B2050. doi:10.1029/2001JB00157.

Weeraratne, D.S., Forsyth, D.W., Yang, Y., Webb, S.C., 2007. Rayleigh wave tomography beneath intraplate volcanic ridges in the South Pacific. J. Geophys. Res. 112, B06303. doi:10.1029/2006JB00440.

Wiens, D.A., Kelley, K.A., Plank, T., 2006. Mantle temperature variations beneath backarc spreading centers inferred from seismology, petrology, and bathymetry. Earth Planet. Sci. Lett. 248, 30-42.
Wolfe, C.J., Solomon, S.C., 1998. Shear-wave splitting and implications for mantle flow beneath the MELT region of the East Pacific Rise. Science 280, 1230-1232.

Yang, Y., Forsyth, D.W., 2006. Regional tomographic inversion of amplitude and phase of Rayleigh waves with 2-D sensitivity kernels. Geophys. J. Int. 166, 1148-1160.

Yang, Y.J., Forsyth, D.W., Weeraratne, D.S., 2007. Seismic attenuation near the East Pacific Rise and the origin of the low-velocity zone. Earth Planet. Sci. Lett. 258, 260-268.

Zhou, Y., Dahlen, F.A., Nolet, G., 2004. Three-dimensional sensitivity kernels for surface wave observables. Geophys. J. Int. 158, 142-168. 